International Conference on New Interfaces for Musical Expression

\title{
Lithium-cli virtual MIDI \\ controller | work in \\ progress
}

Mauricio Carbajal

Published on: Jun 01, 2021

License: Creative Commons Attribution 4.0 International License(CC-BY 4.0). 


\section{Lithium-cli}

\section{Mauricio Carbajal}

\section{PubPub Link}

https://nime.pubpub.org/pub/4fgcok25/draft?access=ffdhmcl9

\section{ABSTRACT}

This project is meant to provide a simple keyboard-only virtual MIDI controller.

You can easily explore chord changes and melodies, learning about diatonic chords, secondary dominants, modal interchange and more.

It is a work in progress, the current version runs exclusively on a terminal and lacks any visualizations besides colored text.

Project website: https://mauriciocarbajal.github.io/lithium-cli/

\section{Program Notes}

lithium-cli: A virtual MIDI controller with CLI interface designed to grasp basic concepts of music harmony.

\section{Media}



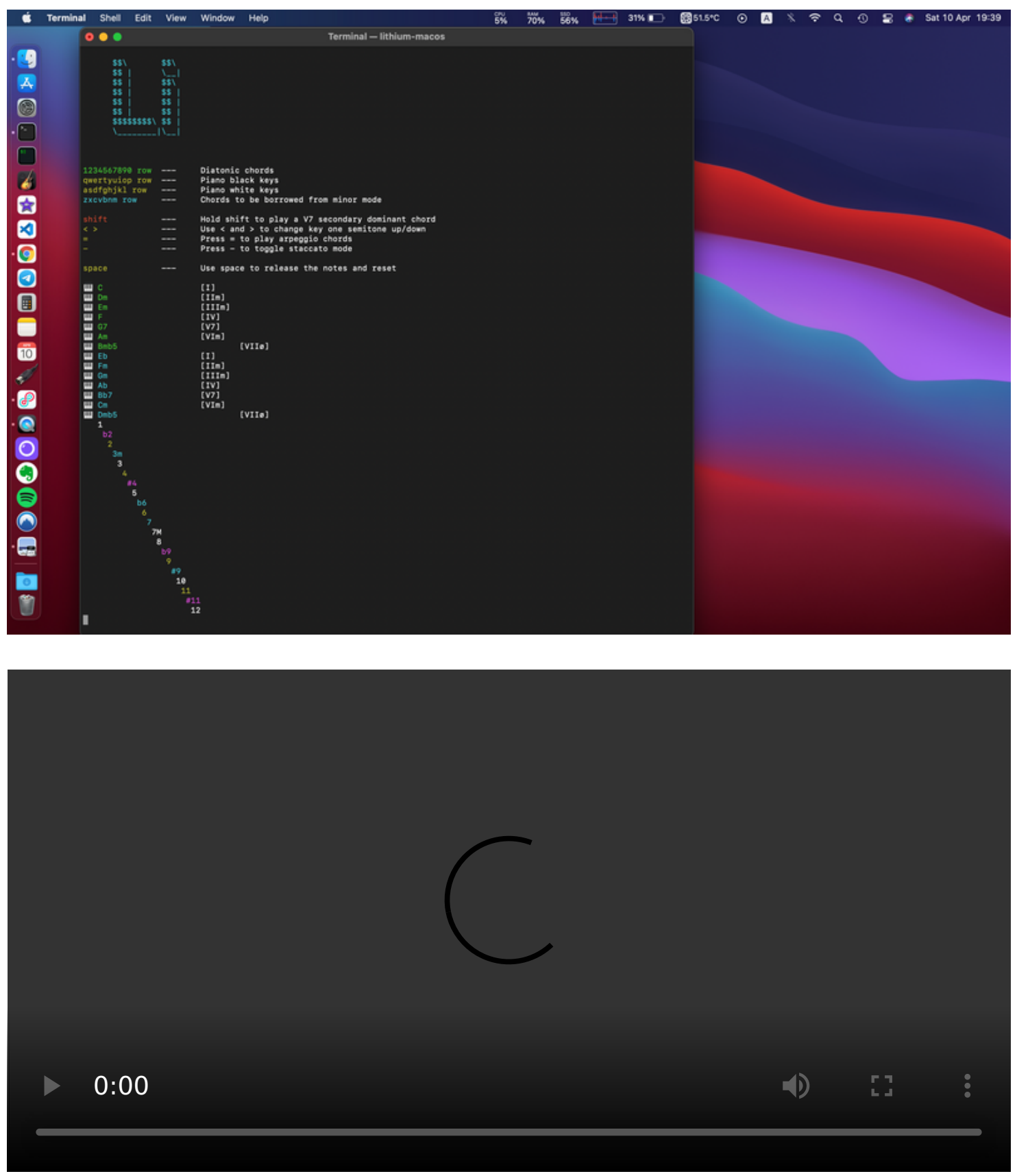